Video lineups in England

Predictors of eyewitness identification decisions from video lineups in England: A field study

In press at Law \& Human Behavior.

\author{
Ruth Horry* \\ Flinders University, Adelaide, Australia \\ Amina Memon \\ Royal Holloway, University of London, Egham, UK \\ Daniel B. Wright \\ Florida International University, Miami, FL \\ Rebecca Milne \\ Portsmouth University, Portsmouth, UK
}

*Ruth.Horry@flinders.edu.au

Author note:

This research was supported by the Economic and Social Research Council and the Scottish Institute of Policing Research.

We thank the police officers and identification officers in the participating forces, without whom this project could not have been completed.

Parts of these data were presented at the $20^{\text {th }}$ Conference of the European Association of Psychology and Law, Gothenburg, Sweden, 2010. 
Video lineups in England

\begin{abstract}
Eyewitness identification decisions from 1,039 real lineups in England were analyzed. Identification procedures have undergone dramatic change in the United Kingdom over recent years. Video lineups are now standard procedure, in which each lineup member is seen sequentially. The whole lineup is seen twice before the witness can make a decision, and the witness can request additional viewings of the lineup. A key aim of this paper was to investigate the association between repeated viewing and eyewitness decisions. Repeated viewing was strongly associated with increased filler identification rates, suggesting that witnesses who requested additional viewings were more willing to guess. In addition, several other factors were associated with lineup outcomes, including the age difference between the suspect and the witness, the type of crime committed, and delay. Overall, the suspect identification rate was $39 \%$, the filler identification rate was $26 \%$, and the lineup rejection rate was $35 \%$.
\end{abstract}


Video lineups in England

\section{Predictors of eyewitness identification decisions from video lineups in England: A field}

$$
\text { study }
$$

\section{Introduction}

Psychologists have been researching eyewitness identification for over a century (Münsterberg, 1908), attempting to understand factors that moderate identification accuracy, and to improve the techniques used to collect identification evidence. Much of this research has been carried out in the laboratory, where participants typically watch an event - either live or videotaped - and after a delay are shown a photographic lineup. Such research has contributed enormously to our understanding of eyewitness memory, and has led to significant improvements in the procedures used in the field (see Wells et al., 2000; Wells, Memon, and Penrod 2006).

However, there are many aspects of a real eyewitness's experience that cannot be captured in the lab, ethically or practically. For example, eyewitnesses may experience significant distress during a real crime, and may experience a direct threat to their physical well-being. Furthermore, delays typically used in eyewitness experiments are relatively brief compared to delays often experienced in the field (Deffenbacher, Bornstein, McGorty, \& Penrod, 2008). These discrepancies have prompted concerns over the generalizability of research from the lab to the field (e.g. Egeth, 1993).

Analyzing real cases is one way to bridge the gap between laboratory research and the field (e.g. Behrman \& Davey, 2001; Memon, Havard, Clifford, Gabbert, \& Watt, 2011; Valentine, Pickering, \& Darling, 2003; Wright \& McDaid, 1996). In such studies, large samples of real eyewitness identifications are collected and statistical models are used to predict the identification outcomes. The sacrifice of experimental control in field data, however, restricts the inferences that can be drawn. These inferences must be associative 
Video lineups in England

rather than causal (Wright, 2006). As a result, data from field studies must always be interpreted with caution, and with full awareness of the noisy, uncontrolled nature of the data.

The procedures used by the police vary from country to country, as well as between jurisdictions within the same country, making it difficult to compare the field studies that have been conducted to date. For example, lineup presentation has varied widely across field studies, from live lineups (Slater, 1994; Valentine et al., 2003; Wright \& McDaid, 1996) to photospreads (Tollestrup, Turtle, \& Yuille, 1994), to video lineups (Memon et al., 2011), to a mix of several procedures (Behrman \& Davey, 2001). Despite this, overall suspect identification rates have been remarkably similar across field studies, ranging from $36 \%$ (Slater, 1994) to $48 \%$ (Behrman \& Davey, 2001) ${ }^{1}$. Filler identification rates, where reported, have varied between $20 \%$ and $24 \%$ (Valentine et al., 2003) ${ }^{2,3}$.

The identification procedures used in England and Wales have changed greatly over the past ten years. At the time of Valentine et al.'s (2003) field study, most lineups in England and Wales were live. Now, the vast majority are presented via video, increasing the efficiency and decreasing the costs associated with lineups (Kemp, Pike, \& Brace, 2001). The video lineup consists of sequentially presented video clips, each lasting approximately fifteen seconds. Each clip begins with a frontal view of the head and shoulders of the lineup member. The lineup member turns to show each profile, and finally looks back at the camera. All clips are filmed under identical conditions, and are stored in a large database, making selection of fillers quick and relatively easy in most cases. According to the Police and Criminal Evidence Act 1984 (PACE) Codes, which govern many aspects of policing in England and Wales, lineups must contain at least eight suitable fillers in addition to the suspect. Most forces in England and Wales use nine person lineups as standard, though some forces use larger lineups. Lineups are run in specialist 'identification suites' by identification officers, who are not involved in any other aspect of the case. 
Video lineups in England

The sequential nature of video lineups could safeguard innocent suspects against mistaken identification. A focus of much research over the past twenty-five years has been the sequential lineup (Lindsay \& Wells, 1985), where in contrast to traditional simultaneous lineups, each lineup member is shown individually. The sequential lineup was developed to prevent witnesses from making relative judgments, in which the lineup members are compared against one another to find the 'best match' to the culprit. Rather, the sequential lineup was thought to encourage absolute judgment strategies, in which each lineup member is directly compared to the witness's memory. There were several key features of the sequential lineup that were all believed to be important for securing identifications based on absolute judgments: the witness was unaware of how many individuals were to be in the lineup; the witness made a decision for each lineup member before moving on to the next; and the witness could not return to a previously rejected lineup member.

A recent meta-analysis showed that participants are less likely to choose from sequential than simultaneous target-absent (TA) lineups (Steblay, Dysart, \& Wells, 2011). However, this may come at a cost to correct identifications from target-present (TP) lineups (see Malpass, Tredoux, \& McQuiston-Surrett, 2009a, 2009b). Ebbesen and Flowe (2002) argued that witnesses become more cautious in general when viewing sequential lineups, making fewer choices from both TP and TA lineups. Debate continues about the robustness of the sequential lineup advantage and its policy implications (see Gronlund, Carlson, Dailey, \& Goodsell, 2009; Lindsay, Mansour, Beaudry, Leach, \& Bertrand, 2009a, 2009b; Malpass, 2006; Malpass et al., 2009a, 2009b).

Since Lindsay and Wells' (1985) original demonstration of the sequential lineup, the basic procedure has been modified across different studies. In particular, the 'stopping rule' has varied across different studies. Lindsay and Wells had their participants view all of the lineup members, even if a positive identification was made, and some other studies have 
Video lineups in England

followed suit (e.g. Carlson, Gronlund, \& Clark, 2008; Wright, Boyd, \& Tredoux, 2001). One consequence of this stopping rule is that witnesses can identify more than one member of the lineup (although the witnesses may be warned that only the first choice will count). Some authors have argued that allowing multiple identifications can in fact provide important information about the reliability of a witness (e.g. Levi \& Jungman, 1995). This is an issue that we will return to in the discussion. Other studies have terminated the procedure at the point when a positive identification is made (e.g. Flowe \& Ebbesen, 2007; Sauer, Brewer, \& Wells, 2008). Consequently, a witness who identifies a filler before the suspect appears in the lineup will not get a chance to view the suspect. For a fuller discussion of sequential lineups and the stopping rule, see Steblay, Dysart et al. (2011).

The identification procedure used in England and Wales is quite different from the sequential procedure used in the lab in several ways: the witness knows beforehand how many individuals will be in the lineup; the witness must view the entire lineup twice before they can report a decision; and the witness can also view whole or part of the lineup again, freezing images as they wish. What effect would we expect these differences to have upon eyewitness identification decisions? Some jurisdictions in North America that have adopted sequential lineups allow multiple 'laps' through the lineup, mainly due to concerns about reduced suspect identification rates using the sequential procedure (Klobuchar, Steblay, \& Caligiuri, 2006; Steblay, Dietrich, Ryan, Raczynski, and James, 2011). Laboratory studies have found that additional lineup laps eliminate the benefits of the sequential procedure, as participants are able to compare the faces against one another in memory (Duckworth \& Kreiner, 2009; Lindsay, Lea, \& Fulford, 1991; MacLin \& Phelan, 2007). Steblay, Dietrich, et al. showed that choosing rates increased from a first lap to a second lap, increasing correct identifications from TP lineups, but also increasing filler identifications from both TP and TA lineups. This effect was strongest for participants with a weak memory of the perpetrator, and 
Video lineups in England

for those who elected to view a second lap versus those who were required to view a second lap. Steblay, Dietrich et al. suggested that participants with stronger memories used the additional lap to confirm their original decisions, whereas participants with weaker memories lowered their decision criterion, frequently switching from lineup rejections to guesses, which were often of fillers. Similar findings were reported in a field study of sequential lineup procedures in Hennepin County, Minnesota (Klobuchar et al., 2006).

However, this effect has not been replicated consistently. Lindsay et al. (1991) found an increase in false identifications only when the second 'lap' was a simultaneous lineup, which was accompanied by a non-significant increase in suspect identifications from TP lineups. Wright et al. (2001) found that witnesses who had previously chosen fillers quite often switched to choosing the target in a subsequent simultaneous lineup, though they did not include a TA condition. Wilcock and Kneller (2011) compared video lineups conducted using the sequential procedure (terminating after a positive identification) with video lineups conducted using PACE Code procedure. When the target was present, the PACE lineups produced higher hit rates. When the target was absent, there were no significant differences between the lineup types. In their field analysis of Scottish video lineups, Memon et al. (2011) found that witnesses who requested additional laps were less likely to identify the suspect, and more likely to identify a filler than witnesses who did not request any additional laps.

A central aim of this field study was to investigate the relationship between repeated viewing of a lineup and the ultimate identification decision. Identification officers recorded whether the witness made a decision after the mandatory two lineup laps, or whether they requested any extra views of the lineup, either whole or in part. Based upon the logic of Steblay, Dietrich, et al. (2011), we expect that witnesses who request additional lineup viewings will have weaker memories than witnesses who make a decision at the first 
Video lineups in England

opportunity. We therefore expect to see higher filler identification rates, possibly accompanied by lower suspect identification rates for these witnesses.

Information was also collected on several characteristics of the witness and the suspect (sex, age, ethnicity). Robust in-group advantages have been demonstrated in the face recognition and eyewitness identification literatures (see Hugenberg, Young, Bernstein, \& Sacco, 2010; and Sporer, 2001, for reviews). We therefore recorded whether the witness and suspect were of the same sex or from the same ethnic group, and the age difference between the witness and the suspect. In addition, we collected information on the type of crime committed, on the delay between the crime and the lineup, and on the suspect's position in the lineup. Finally, we recorded whether the witness was also a victim of the crime.

The PACE Codes ensure a high degree of consistency in procedures between police forces in England and Wales. Therefore, the majority of the variables in this analysis were estimator variables, which are outside of the control of the legal system (Wells, 1978). Due to the uncontrolled nature of field data, and the inevitability of inter-correlations among the variables, we refrained from making any predictions about individual variables. However, the effects of many of these variables on eyewitness identification accuracy are discussed in depth elsewhere (see, for example, Lindsay, Ross, Read, \& Toglia, 2007).

In any field study, there is an absence of 'ground truth'. It is difficult in most cases to say with certainty which suspects are guilty and which are innocent. Behrman and Davey (2001) recorded whether there was any corroborating evidence against the suspect, and whether that evidence was of 'minimal' or 'substantive' probative value. Suspect identification rates were higher when there was corroborating evidence of guilt than when there was no corroborating evidence, possibly because those suspects were, in fact, more likely to be guilty. The use of corroboration to estimate a suspect's guilt relies on the assumption of evidentiary independence. However, incriminating evidence from one source 
Video lineups in England

(e.g. confessions, DNA evidence) can influence the way in which other evidence is processed (Dror \& Charlton, 2006; Hasel \& Kassin, 2009; Simon, Snow, \& Read, 2004). Even if information is available on corroborating evidence, field data must be interpreted carefully. Of the three possible outcomes from a lineup (suspect identification, filler identification, or lineup rejection), a filler identification is the only outcome for which accuracy is known ${ }^{4}$. Filler identifications are reported here, as in many field studies, as a useful index of guessing biases. Suspect identifications rates are also reported, though in the absence of ground truth, suspect identifications cannot be equated with accuracy (Wells, 2008).

\section{Method}

A modified version of the questionnaire used by Memon et al. (2011) was developed with the guidance of a senior police officer. The questionnaires were completed by the ID Officer responsible for each lineup.

\section{Questionnaire composition}

The questionnaire was designed to create minimal work for the ID Officers. The questionnaire was kept to a single side of paper, and used multiple-choice tick boxes wherever possible. Questionnaire items were chosen if they could be answered quickly and easily, so many possible variables were excluded (such as weapon focus, alcohol intoxication, view of suspect). No information was recorded which would reveal the identity of the witness or the suspect. Where there were multiple witnesses and/or suspects to the same crime event, the ID officer was asked to indicate this clearly, and to attach related forms together.

\section{Sample}

Data from 1,575 lineups were collected. Cases in which the suspect was known to the witness and cases with missing data were excluded, leaving 1,039 cases in the final analyses. These cases included 606 distinct crime events with 740 suspects and 874 witnesses. Overall, 
Video lineups in England

the suspect was chosen in 406 cases (39.08\%), a filler was chosen in 273 cases (26.28\%), and the lineup was rejected in 360 cases $(34.65 \%)$.

The data were collected from five specialist identification suites in England. Within each suite, one questionnaire was completed for every video lineup run over a three month period. The start dates for each suite were staggered, so the data collection began in September 2009 and ended in April 2010. The catchment areas for these suites included inner city and rural communities from geographically distant parts of the country, which varied widely in socio-economic demographics and in the types of crimes that were committed (see Table 1). Minority ethnicity witnesses accounted for $54 \%$ of the witnesses from Force 4 , and just $4 \%$ of the witnesses from Force 2. Minority ethnicity suspects accounted for $73 \%$ of suspects from Force 3, and just $7 \%$ of suspects from Force 2. Robbery rates also varied markedly, making up $45 \%$ of the crimes from Force 3 , and just $3 \%$ of the crimes from Force

2. The sizeable differences in suspect identifications (from $30 \%$ in Force 5 to $49 \%$ in Force 2) and filler identifications (from $23 \%$ in Forces 1 and 2 to $38 \%$ in Force 5) could be a reflection of these demographic variations. Of course, they could also be accounted for by a host of other unknown factors, such as differences in investigative strategies, which could produce different base rates of culprit-presence across the forces.

\section{Results}

Each lineup in the sample was assigned a unique trial code, and was also assigned a witness number, a suspect number, and a crime number. All trials that shared the same witness were given the same witness code (and trials sharing a suspect shared a suspect code). This allowed for the use of multilevel modelling (MLM). The lme4 package created for R (Bates \& Maechler, 2010) was used, which is a freely available program for statistical analyses (http://www.r-project.org). 
Video lineups in England

MLM should be used on datasets in which cases are cross-classified (Wright \& London, 2009). Within this dataset, witnesses were cross-classified with suspects. That is, the same suspect was sometimes seen by more than one witness, and the same witness sometimes saw more than one suspect. The data are therefore not independent, and it would be inappropriate to use traditional statistics which would assume independence. By using MLM, witnesses and suspects can be specified as random effects, where the regression intercepts are allowed to vary for each witness and for each suspect.

The analyses were conducted using multilevel logistic regression. Two separate models were created, one for predicting suspect identifications, and one for predicting filler identifications. As the three lineup outcomes (suspect identifications, filler identifications, and lineup rejections) are not independent, only suspect and filler identifications were analyzed. We began with models containing the main effects of each predictor variable. These models contained ten categorical variables: Witness Sex, Witness Ethnicity (White, Black, South Asian, Other), Witness-Victim (Victim vs. Bystander), Suspect Sex, Suspect Ethnicity (White, Black, South Asian, Other), Own-Ethnicity (own-ethnic lineup vs. cross-ethnic lineup), Own-Sex (own-sex lineup vs. cross-sex lineup), Crime Type (violence, robbery, burglary, sexual offences, other offences), Lineup Position, and Repeat Viewing (no additional views vs. at least one additional view). There were also four continuous variables: Witness Age (years), Suspect Age (years), Age Difference (decades) ${ }^{5}$, and Delay (years). At each stage of the analysis, the variable with the smallest predictive value was removed, and the goodness of fit of the model was compared before and after removal of the variable. This process was repeated until none of the variables could be removed without significantly reducing the goodness of fit of the model.

Odds ratios (ORs) are reported as measures of effect size for categorical variables. The odds of a given outcome (e.g. a suspect identification) are first calculated for each level of the 
Video lineups in England

comparison. For example, the odds of a suspect identification when the witness is female might be .50 , and the odds of a suspect identification when the witness is male might be .40 . The OR is the ratio between these two odds: in this case, $.50 / .40=1.25$. This shows that the odds of a female witness choosing the suspect are 1.25 times higher than the odds of a male witness choosing the suspect. An OR of 1.00 shows that the odds are the same for both groups.

\section{Suspect identifications}

The most parsimonious model for predicting suspect identifications included five variables: Suspect Sex, $\chi^{2}(1, N=1039)=7.17, p=.007$; Suspect Ethnicity, $\chi^{2}(3, N=1039)=$ 13.66, $p=.003$; Age Difference, $\chi^{2}(1, N=1039)=39.87, p<.001$; Crime Type, $\chi^{2}(4, N=$ $1039)=11.66, p=.02$; and Delay, $\chi^{2}(1, N=1039)=4.88, p=.03$. Table 2 shows the frequencies of suspect identifications across the three categorical predictors in this model.

As Table 2 shows, female suspects were more likely to be chosen than male suspects, $z$ $=2.80, p=.005, O R=1.47$. White suspects were more likely to be chosen than Black suspects, $z=3.78, p<.001, O R=1.50$. Robbery suspects were less likely to be chosen than suspects from any other group: Sexual Offences, $z=2.28, p=.03, O R=1.48$; Burglary, $z=$ $2.05, p=.04, O R=1.35$; Violence, $z=2.00, p=.05, O R=1.46$; Other, $z=3.23, p=.001, O R$ $=1.58$.

The association between delay and suspect identifications was negative, $\beta=-0.59, S E=$ $.33, p=.07$, meaning that the likelihood of a suspect being identified decreased over time. In our sample, delay ranged from 0 days to 3087 days (almost nine years), with a median delay of 31 days. Suspect identification rates are plotted as a function of delay in Figure 1. For illustrative purposes, the cases have been grouped together into discrete delay periods. As the figure shows, the relationship was fairly weak and noisy. However, it is clear that the highest suspect identification rates were found within a couple of weeks of the crime, and the lowest 
Video lineups in England

suspect identification rate was for lineups conducted after a substantial delay (approximately six months or more).

The association between age difference and suspect identifications was also negative, $\beta$ $=-0.52, S E=.08, p<.001$. Age difference in our sample ranged from 0 to 70 years, with a median age difference of 7 years. Figure 2 shows suspect identification rates as a function of age difference. It is clear from Figure 2 that the likelihood of a suspect being chosen decreases as the age difference between the witness and the suspect increases. As the vast majority of the suspects were reasonably young ( $80 \%$ were under 30$)$, most of the cases with large age differences involved older witness viewing younger suspects.

\section{Filler identifications}

The most parsimonious model for predicting filler identifications included four

variables: Witness Ethnicity, $\chi^{2}(3, N=1039)=8.09, p=.04$; Age Difference, $\chi^{2}(1, N=1039)$ $=4.43, p=.04$; Crime Type, $\chi^{2}(4, N=1039)=10.02, p=.04 ;$ and Repeated Viewing, $\chi^{2}(1, N$ $=1039)=62.19, p<.001$. Table 3 shows the frequencies of filler identifications across the three categorical variables in the model.

Witnesses who requested at least one additional viewing of the lineup were almost two and a half times more likely to choose a filler than those who did not, $z=7.77, p<.001$, $O R=2.40$. White witnesses were more likely to choose fillers than South Asian witnesses, $z$ $=2.63, p=.008, O R=1.64$. Fillers were more likely to be chosen by witnesses to violent crimes than to burglaries, $z=2.20, p=.03, O R=1.18$, or other types of crimes, $z=2.76, p=$ $.006, O R=1.37$.

The association between age difference and filler identifications was positive, $\beta=$ $0.17, S E=.08, p=.03$. This association is shown in Figure 3. 
Video lineups in England

\section{Associations between predictors}

To explore the relationships between the categorical variables, Cramér's $V$ was calculated for each pair of predictors (see Table 4). Cramér's $V$ varies between 0 and 1. Higher values reflect stronger relationships between the variables. As one would expect, many of the variables were associated with one another. Witness sex was strongly associated with own-sex identifications. This reflects the fact that the vast majority (over 93\%) of the suspects were male. As a result, male witnesses were far more likely to view own-sex lineups $(95.38 \%)$ than were female witnesses $(11.42 \%)$. Own-ethnicity identifications were strongly associated with both witness ethnicity and suspect ethnicity. White witnesses, being the majority ethnic group in England, were much more likely to view an own-ethnic lineup (83.12\%) than a cross-ethnic lineup (16.88\%). Black witnesses were much more likely to view a cross-ethnic lineup (82.17\%) than an own-ethnic lineup (17.83\%), while South Asian witnesses viewed own- and cross-ethnic lineups with equal frequency within this sample. White suspects were more likely to be viewed by White witnesses $(70.62 \%)$ than by witnesses from minority groups (29.37\%). South Asian suspects were more likely to be viewed by witnesses from other ethnic groups (71.69\%) than by witnesses from their own ethnic group (28.31\%), while Black suspects were about equally likely to be viewed by witnesses from their own group (51.11\%) and witnesses from other groups (48.89\%). Crime type was moderately associated with most of the witness and suspect characteristics, indicating that there were demographic differences in the types of crimes that were committed and witnessed by people from different age, sex, and ethnic groups.

Bivariate correlations were run to examine the relationships between the continuous variables. The age difference between the witness and suspect was strongly correlated with the age of the witness $(r=.77)$. This shows that the larger age differences typically involved older witnesses. Given that most of the suspects were relatively young ( $80 \%$ under 30 , and 
Video lineups in England

$33 \%$ under 18), this is not surprising. The high degree of multicollinearity between the age of the witness and the age difference between the witness and the suspect may account for why witness age was not a significant predictor of lineup outcomes.

\section{Discussion}

A central aim of this field study was to explore the relationship between repeated viewing of a lineup and the identification decision. In England and Wales, the PACE Codes state that witnesses must view the entire lineup twice before they are allowed to make a decision. They may request additional views of the lineup, either wholly or in part. We found that witnesses who requested at least one additional viewing of the lineup were two and a half times more likely to identify fillers than witnesses who did not request any additional lineup viewings. Filler identifications are known errors, which will not lead to prosecution of the identified party. Yet high filler identification rates cast doubt on the reliability of suspect identifications, as they suggest high guessing rates. Our findings are consistent with laboratory research, which has shown that additional lineup laps or the request to view the lineup again increase filler identifications from target-absent lineups (Duckworth \& Kreiner, 2009; Lindsay et al., 1991; MacLin \& Phelan, 2007; Steblay, Dietrich, et al., 2011).

There are two reasons why witnesses might request an additional lineup lap: to confirm a decision that has already been made, or to continue studying the faces until they feel that they can make a decision (Steblay, Dietrich, et al., 2011). Given that all of the witnesses had already seen the entire lineup twice, providing an opportunity for the confirmation of an initial choice, most of the witnesses who asked for additional viewings probably did so because they had been unable to make a choice previously. Ultimately, these witnesses were more likely to guess, possibly because their memories of the culprit were weak and they had strong desires to choose somebody from the lineup. This could have had devastating consequences if the lineup was, in fact, culprit absent, and the innocent suspect 
Video lineups in England

was chosen. There is clearly a need to review the current PACE Codes on repeated viewing of lineups. If witnesses are to be allowed additional views, then perhaps they should be asked to provide their reasons for why they would like to see the lineup again. This might help to distinguish between witnesses who wish to confirm a decision and witnesses who were unable to make a decision on the first two passes through the lineup (Steblay, Dietrich, et al.).

In addition to the associations with repeated viewing, there were several other variables that predicted suspect and/or filler identifications. For example, violent crimes and sexual offences were associated with the highest filler identification rates. The stress associated with these crimes may moderate accuracy through physiological changes in the adrenological system. Stress-related decreases in identification accuracy have been documented in two field experiments (Morgan et al., 2004; Valentine \& Mesout, 2009). Both studies found increased filler identification rates coupled with decreased accurate suspect identification rates under conditions of high stress (see Deffenbacher, Bornstein, Penrod, \& McGorty, 2004, and Pickel, 2007, for reviews of the relationship between arousal and identification accuracy). Our results fit with findings from field experiments, though we must refrain from drawing any causal conclusions. It is possible that culprit-present base rates differed for crimes that were more or less serious, due to differential allocation of police resources for more or less serious crimes.

We found that suspect identification rates decreased and filler identification rates increased as the age difference between the witness and the suspect increased. However, as our suspects were reasonably young, most of the larger age differences involved older witnesses identifying younger suspects. The multicollinearity between age difference and witness age was very high, making it impossible to tease apart age-related declines from an own-age bias or in-group advantage that has been reported in experimental studies (Harrison \& Hole, 2009; Memon, Bartlett, Rose, \& Gray, 2003; Perfect \& Harris, 2003; Wright \& 
Video lineups in England

Stroud, 2002). This association may have been produced by a combination of social biases and cognitive and perceptual declines across the life span. Memon et al. (2003), for example, found that older witnesses were generally less accurate than younger witnesses, but that the magnitude of this difference was smaller when the suspect was of a similar age to the older witnesses (see also Havard \& Memon, 2009).

A key aim of introducing video lineups in England and Wales was to reduce the delay between a suspect becoming known and the conduct of an identification procedure by as much as possible (Kemp et al., 2001). The British police are doing an excellent job in this regard. In this sample, approximately $23 \%$ of lineups were conducted within one week of the crime, and a further $12 \%$ were conducted within two weeks of the crime. We found a significant association between delay and suspect identification rates, though the relationship was quite weak and noisy. Some previous field studies have found sharp declines in memory within days of the crime (Behrman \& Davey, 2001; Tollestrup et al., 1994), while others have not found any significant association between delay and suspect identifications (Valentine et al., 2003; Wright \& McDaid, 1996). While causal relationships between delay and memory are clearly evident in the laboratory (Deffenbacher et al., 2008), confounds with other factors (e.g. crime type, selection of witnesses) may obscure this relationship in the field.

Sequential procedures in some studies and in some North American jurisdictions allow witnesses to make multiple choices from a lineup. Multi-choice lineups could allow investigators to attach appropriate weight to an eyewitness on the basis of their final selection (Levi \& Jungman, 1995). A witness who identifies the suspect, and only the suspect, should be given greater weight than a witness who chooses the suspect and a filler. The PACE procedure provides no opportunity for multiple selections (though of course, a witness could say something like "it could be number 2 or number 5"), and it is difficult to envisage investigators being receptive to this idea, for fear of weakening positive identifications of the 
Video lineups in England

suspect (see Leippe \& Wells, 1995, for a discussion of this issue). Yet the logic of multiple lineup choices is certainly compelling, and is deserving of empirical attention.

Conspicuously absent from our set of predictor variables is witness confidence.

Laboratory research has shown that, for choosers, confidence is positively associated with identification accuracy (Brewer \& Wells, 2006; Sporer, Penrod, Read, \& Cutler, 1995; Weber \& Brewer, 2004). Recording witness confidence at the time of the identification is crucial for assessing the reliability of a witness, as confidence is easily inflated by exposure to postevent information (e.g. Wells \& Bradfield, 1998). For this reason, recording witness confidence was a central recommendation of the National Institute of Justice Guidelines in the US (Technical Working Group for Eyewitness Evidence, 1999). It was also a recommendation of the British Psychological Society (2007) to the UK Home Office for changes to PACE (http://www.bps.org.uk/downloadfile.cfm?file_uuid=32109AE2-1143DFD0-7E9E-4B5091B061CA\&ext=pdf). However, the PACE Codes do not require officers to ask for confidence judgments. Therefore, unless a witness spontaneously makes some statement of confidence, there will be no record of initial certainty. This is clearly a serious oversight of the PACE Codes, as defence lawyers will be unable to detect post-identification inflations in confidence. In the high-profile case of Barry George, who was convicted and later acquitted of the murder of the British television presenter Jill Dando, two witnesses who initially made 'tentative' identifications of the suspect testified to being sure of their decisions in court ( $R$ v. George, 2002, EWCA Crim 1923). Had initial confidence judgments been recorded, the jury would have been aware of the uncertainty with which these witnesses had made their initial identifications.

Field data such as those presented here can complement experimental data from the laboratory. Patterns of responding across large numbers of witnesses of diverse ages and ethnic backgrounds can be compared. Many of these witnesses will have experienced 
Video lineups in England

distressing events that could never be simulated in the laboratory. Of course, one must bear in mind the limitations of field data, including the absence of ground truth regarding suspect guilt (Wells, 2008), multicollinearity between variables, and potential confounds with unrecorded variables. These limitations highlight the need to avoid drawing causal inferences from field data (Wright, 2006). Nevertheless, these data add to our existing knowledge of eyewitness identification, while also raising questions for future research.

In conclusion, this field study examined identification decisions from over one thousand real lineups conducted in England. We found clear evidence that repeated viewing of lineups increases guessing rates, which places innocent suspects at risk. We also found associations between lineup outcomes and a constellation of estimator variables. Of all identifications made within this sample, approximately forty per cent were of fillers. These data add to a growing body of research showing that witness guessing is not restricted to experimental situations with disinterested college students who know that their choices carry no consequences. The overwhelming evidence that has mounted up for the inherent fallibility of eyewitnesses is difficult to reconcile with the weight that justice systems continue to attach to this type of evidence. Social scientists and police forces should continue to work together in order to maximise the reliability of identification procedures in Britain and in the rest of the world. 
Video lineups in England

\section{References}

Bates, D. \& Maechler, M. (2010). Linear mixed-effects models using S4 classes. R package version 0.999375-37. http://CRAN.R-project.org/package=lme4.

Behrman, B. W. \& Davey, S. L. (2001). Eyewitness identification in actual criminal cases: An archival analysis. Law \& Human Behavior, 25, 475-491. doi: 10.1023/A:1012840831846.

Brewer, N. \& Wells, G. L. (2006). The confidence-accuracy relationship in eyewitness identification: Effects of lineup instructions, foil similarity, and target-absent base rates. Journal of Experimental Psychology: Applied, 12, 11-30.

Carlson, C. A., Gronlund, S. D., \& Clark, S. E. (2008). Lineup composition, suspect position, and the sequential lineup advantage. Journal of Experimental Psychology: Applied, 14, 118-128. doi: 10.1037/1076-898X.14.2.118.

Deffenbacher, K. A., Bornstein, B. H., McGorty, E. K., \& Penrod, S. D. (2008). Forgetting the once-seen face: Estimating the strength of an eyewitness's memory representation. Journal of Experimental Psychology: Applied, 14, 139-150. doi: 10.1037/1076898X.14.2.139.

Deffenbacher, K. A., Bornstein, B. H., Penrod, S. D., \& McGorty, E. K. (2004). A metaanalytic review of the effects of high stress on eyewitness memory. Law \& Human Behavior, 28, 687-706. doi: 10.1007/s10979-004-0565-x.

Dror, I. E. \& Charlton, D. (2006). Why experts make errors. Journal of Forensic Identification, 56, 600-616.

Duckworth, T. S. \& Kreiner, D. S. (2009). Effect on eyewitness accuracy when eyewitnesses are told versus not told that they will be allowed a second viewing. Journal of Police \& Criminal Psychology, 24, 30-35. doi: 10.1007/s11896-008-9034-7. 
Video lineups in England

Ebbesen, E. B. \& Flowe, H. D. (2002). Simultaneous v. Sequential lineups: What do we really know? Accessed online (25 ${ }^{\text {th }}$ August 2010): http://www.psy.ucsd.edu/\%7eeebbesen/SimSeq.htm.

Egeth, H. E. (1993). What do we not know about eyewitness identification? American Psychologist, 48, 577-580. doi: 10.1037/0003-066X.48.5.553.

Flowe, H. D. \& Ebbesen, E. B. (2007). The effect of lineup member similarity on recognition accuracy in simultaneous and sequential lineups. Law \& Human Behavior, 31, 33-52. doi: 10.1007/s10979-006-9045-9.

Gronlund, S. D., Carlson, C. A., Dailey, S. B., \& Goodsell, C. A. (2009). Robustness of the sequential lineup advantage. Journal of Experimental Psychology: Applied, 15, 140152. doi: $10.1037 / \mathrm{a} 0015082$.

Harrison, V. \& Hole, G. (2009). Evidence for a contact-based explanation of the own-age bias in face recognition. Psychonomic Bulletin \& Review, 16, 264-269. doi: 10.3758/PBR.16.2.264.

Hasel, L. E. \& Kassin, S. M. (2009). On the presumption of evidentiary independence: Can confessions corrupt eyewitness identifications? Psychological Science, 20, 122-126. doi: 10.1111/j.1467-9280.2008.02262.x.

Havard, C. \& Memon, A. (2009). The influence of face age on identification from a video line-up: A comparison between older and younger adults. Memory, 17, 847-859. doi: $10.1080 / 09658210903277318$.

Hugenberg, K., Young, S. G., Bernstein, M. J., \& Sacco, D. F. (2010). The categorizationindividuation model: An integrative account of the other race recognition deficit. Psychological Review, 117, 1168-1187. doi: 10.1037/a0020463.

Kemp, R. I., Pike, G. E., \& Brace, N. A. (2001). Video-based identification procedures: Combining best practice and practical requirements when designing identification 
Video lineups in England

systems. Psychology, Public Policy, \& Law, 7, 802-807. doi: 10.1037//10768971.7.4.802.

Klobuchar, A., Steblay, N. K. M., \& Caligiuri, H. L. (2006). Improving eyewitness identifications: Hennepin County's blind sequential lineup pilot project. Cardazo Public Law, Policy, and Ethics Journal, 2, 381-414.

Leippe, M. R. \& Wells, G. L. (1995). Should we be partial to partial identification? Commentary on the Levi-Jungman proposal. Criminal Justice \& Behavior, 22, 373385. doi: $10.1177 / 0093854895022004002$.

Levi, A. M. \& Jungman, N. (1995). The police lineup: Basic weaknesses, radical procedures. Criminal Justice \& Behavior, 22, 347-372. doi: 10.1177/0093854895022004001.

Lindsay, R. C. L., Lea, J. A., \& Fulford, J. A. (1991). Sequential lineup presentation: Technique matters. Journal of Applied Psychology, 76, 741-745. doi: 10.1037/00219010.76.5.741.

Lindsay, R. C. L., Mansour, J. K., Beaudry, J. L., Leach, A-M., \& Bertrand, M. I. (2009a). Sequential lineup presentation: Patterns and policy. Legal \& Criminological Psychology, 14, 13-24. doi: 10.1348/135532508X382708.

Lindsay, R. C. L., Mansour, J. K., Beaudry, J. L., Leach, A-M., \& Bertrand, M. I. (2009b). Beyond sequential presentation: Misconceptions and misrepresentations of sequential lineups. Legal \& Criminological Psychology, 14, 31-34. doi: 10.1348/ $135532508 \times 382104$.

Lindsay, R. C. L., Ross, D. F., Read, J. D., \& Toglia, M. P. (Eds.) (2007). The handbook of eyewitness psychology, volume II: Memory for people. New Jersey: Lawrence Erlbaum Associates. 
Video lineups in England

Lindsay, R. C. L. \& Wells, G. L. (1985). Improving eyewitness identifications from lineups: Simultaneous versus sequential lineup presentation. Journal of Applied Psychology, 70, 556-564. doi: 10.1037/0021-9010.70.3.556.

MacLin, O. H. \& Phelan, C. M. (2007). PC_Eyewitness: Evaluating the New Jersey method. Behavior Research Methods, 39, 242-247.

Malpass, R. S. (2006). A policy evaluation of simultaneous and sequential lineups. Psychology, Public Policy, \& Law, 12, 394-418. Doi: 10.1037/1076-8971.1.12.4.394.

Malpass, R. S., Tredoux, C. G., \& McQuiston-Surrett, D. (2009a). Public policy and sequential lineups. Legal \& Criminological Psychology, 14, 1-12. doi: $10.1348 / 135532508 X 384102$.

Malpass, R. S., Tredoux, C. G., \& McQuiston-Surrett, D. (2009b). Response to Lindsay, Mansour, Beaudry, Leach, and Bertrand's “Sequential lineup presentation: Patterns and policy”. Legal \& Criminological Psychology, 14, 25-30. doi: $10.1348 / 135532508 X 384094$.

Mecklenburg, S. H. (2006). Report to the legislature of the State of Illinois: The Illinois pilot program on double-blind, sequential lineup procedures. Springfield, IL: Illinois State Police.

Memon, A., Bartlett, J., Rose, R., \& Gray, C. (2003). The aging eyewitness: Effects of age on face, delay, and source-memory ability. Journal of Gerontology: Psychological Sciences, 58B, P338-P345. doi: 10.1093/geronb/58.6.P338.

Memon, A., Havard, C., Clifford, B., Gabbert, F., \& Watt, M. (2011). A field evaluation of the VIPER system: A new technique for eliciting eyewitness evidence. Psychology, Crime, \& Law. Published online $1^{\text {st }}$ February 2011.

Morgan, C. A., Hazlett, G., Doran, A., Garrett, S., Hoyt, G., Thomas, P., Baranoski, M., \& Southwick, S. M. (2004). Accuracy of eyewitness memory for persons encountered 
Video lineups in England

during exposure to highly intense stress. International Journal of Law \& Psychiatry, 27, 265-279. doi: 10.1016/j.ijlp.2004.03.004.

Münsterberg, H. (1908). On the witness stand. New York: Doubleday, Page \& Company.

Perfect, T. J. \& Harris, L. J. (2003). Adult age differences in unconscious transference: Source confusion or identity blending? Memory \& Cognition, 31, 570-580.

Pickel, K. L. (2007). Remembering and identifying menacing perpetrators: Exposure to violence and the weapon focus effect. In R. C. L. Lindsay, D. F. Ross, J. D. Read, \& M. P. Toglia (Eds.). The handbook of eyewitness psychology, volume II: Memory for people. (pp. 339-360). New Jersey: Lawrence Erlbaum Associates.

Sauer, J. D., Brewer, N., \& Wells, G. L. (2008). Is there a magical time boundary for diagnosing eyewitness identification accuracy in sequential line-ups? Legal \& Criminological Psychology, 13, 123-135. doi: 10.1348/135532506X159203.

Schacter, D. L., Dawes, R., Jacoby, L. L., Kahneman, D., Lempert, R., Roediger, H. L., \& Rosenthal, R. (2008). Policy forum: Studying eyewitness investigations in the field. Law \& Human Behavior, 32, 3-5. doi: 10.1007/s10979-007-9093-9.

Simon, D., Snow, C. J., \& Read, S. J. (2004). The redux of cognitive consistency theories: Evidence judgments by constraint satisfaction. Journal of Personality \& Social Psychology, 86, 814-837. doi: 10.1037/0022-3514.86.6.814.

Slater, A. (1994). Identification lineups: A scientific evaluation. Police Research Award Scheme. London: Police Research Group, Home Office.

Spinney, L. (2008). Eyewitness identification: Line-ups on trial. Nature, 453, 442-444. doi: $10.1038 / 453442 \mathrm{a}$.

Sporer, S. L. (2001). Recognizing faces of other ethnic groups: An integration of theories. Psychology, Public Policy, \& Law, 7, 36-97. doi: 10.1037//1076-8971.7.1.36. 
Video lineups in England

Sporer, S. L., Penrod, S., Read, D., \& Cutler, B. (1995). Choosing, confidence, and accuracy: A meta-analysis of the confidence-accuracy relation in eyewitness identification studies. Psychological Bulletin, 118, 315-327. doi: 10.1037/0033-2909.118.3.315.

Steblay, N. K. (2008). Commentary on "Studying eyewitness investigations in the field": A look forward. Law \& Human Behavior, 32, 11-15. doi: 10.1007/s10979-007-9105-9.

Steblay, N. K. (2011). What we know now: The Evanston Illinois field lineups. Law \& Human Behavior, 35, 1-12. doi: 10.1007/s10979-009-9207-7.

Steblay, N. K., Dietrich, H. L., Ryan, S. L., Raczynski, J. L., \& James, K. A. (2011). Sequential lineup laps and eyewitness accuracy. Law \& Human Behavior. Published online $16^{\text {th }}$ July 2010 .

Steblay, N., Dysart, J., \& Wells, G. L. (2011). Seventy-two tests of the sequential lineup superiority effect: A meta-analysis and policy discussion. Psychology, Public Policy, \& Law, 17, 99-139. doi: 10.1037/a0021650.

Technical Working Group for Eyewitness Evidence (1999). Eyewitness Evidence: A Guide for Law Enforcement. Washington, DC: United States Department of Justice, Office of Justice Programs.

Tollestrup, P. A., Turtle, J. W. \& Yuille, J. C. (1994). Actual victim and witnesses to robbery and fraud: An archival analysis. In: Ross, D. F., Read, J. D. \& Toglia, M. P. (Eds.) Adult eyewitness testimony: Current trends and developments. (pp. 144 - 160). Cambridge: Cambridge University Press.

Valentine, T. \& Mesout, J. (2009). Eyewitness identification under stress in the London Dungeon. Applied Cognitive Psychology, 23, 151-161. doi: 10.1002/acp.1463.

Valentine, T., Pickering, A., \& Darling, S. (2003). Characteristics of eyewitness identification that predict the outcome of real lineups. Applied Cognitive Psychology, 17, 969-993. doi: 10.1002/acp.939. 
Video lineups in England

Weber, N. \& Brewer, N. (2004). Confidence-accuracy calibration in absolute and relative face recognition judgments. Journal of Experimental Psychology: Applied, 10, 156-172.

Wells, G. L. (1978). Applied eyewitness-testimony research: System variables and estimator variables. Journal of Personality \& Social Psychology, 36, 1546-1557. doi: 10.1037/0022-3514.36.12.1546.

Wells, G. L. (2008). Field experiments on eyewitness identification: Towards a better understanding of pitfalls and prospects. Law \& Human Behavior, 32, 6-10. doi: 10.1007/s10979-007-9098-4.

Wells, G. L. \& Bradfield, A. L. (1998). “Good, you identified the suspect”: Feedback to eyewitnesses distorts their reports of the witnessing experience. Journal of Applied Psychology, 83, 360-376.

Wells, G. L., Malpass, R. S., Lindsay, R. C. L., Fisher, R. P., Turtle, J. W., \& Fulero, S. M. (2000). From the lab to the police station: A successful application of eyewitness research. American Psychologist, 55, 581-598. doi: 10.1037//0003-066X.55.6.58.

Wells, G. L., Memon, A. \& Penrod, S. D. (2006) Eyewitness Evidence: Improving its Probative Value. Psychological Science in the Public Interest, 7, 45-75.

Wilcock, R. \& Kneller, W. (2011). A comparison of presentation methods of video identification parades. Applied Cognitive Psychology. doi: 10.1002/acp.1754. Published online $17^{\text {th }}$ October 2010.

Wright, D. B. (2006). Causal and associative hypotheses in psychology: Examples from eyewitness testimony research. Psychology, Public Policy, \& Law, 12, 190-213.

Wright, D. B., Boyd, C. E., \& Tredoux, C. G. (2001). A field study of own-race bias in South Africa and England. Psychology, Public Policy, \& Law, 7, 119-133. doi: 10.1037//1076-8971.7.119. 
Video lineups in England

Wright, D.B. \& London, K. (2009). Multilevel modelling: Beyond the basic applications. British Journal of Mathematical and Statistical Psychology, 62, 439-456.

Wright, D. B. \& McDaid, A. T. (1996). Comparing system and estimator variables using data from real lineups. Applied Cognitive Psychology, 10, 75-84. doi: 10.1002/(SICI)10990720(199602)10:1<75::AID-ACP364>3.0.CO;2-E.

Wright, D. B., \& Stroud, J. N. (2002). Age differences in lineup identification accuracy: People are better with their own age. Law \& Human Behavior, 26, 641-654. doi: 10.1023/A:1020981501383. 
Video lineups in England

\section{Footnotes}

1. Behrman and Davey's (2001) study included a large number of cases that had been referred to them. This method of sampling likely inflated the suspect identification rate in their sample.

2. Memon et al. (2011) found a high filler identification rate of $41.9 \%$ in cases where the suspect was a stranger to the witness. This high filler identification rate may have been due to the wording of the questionnaire, which separated identification outcomes into: positive identification, negative identification, and no identification. While the "negative identification" category was intended to capture filler identifications only, some officers may have included lineup rejections in this category, inflating the filler identification rate.

3. One notable exception to this pattern of results is the Illinois Pilot Program (the "Illinois study"), a year-long field experiment carried out in 2005 to assess the usefulness of the double-blind sequential lineup in practice (Mecklenburg, 2006). Suspect identification rates were at $60 \%$ for simultaneous lineups and $45 \%$ for sequential lineups and filler identification rates were very low, at $9.2 \%$ for sequential lineups, and just $2.8 \%$ for simultaneous lineups. However, Wells (2008) speculated that "tentative" filler identifications may not have been recorded, deflating the true filler identification rates. The Illinois study has also been heavily criticised on several other grounds (see Schacter et al. 2008; Spinney, 2008; Steblay, 2008, 2011; Wells, 2008). Given the controversy over the Illinois Study, we do not discuss it further here.

4. This will only be true if all fillers in a lineup are known to be innocent, as is the case in the UK and in most other jurisdictions.

5. Age difference was coded as an absolute difference, irrespective of whether the witness or the suspect was older. Most of the suspects were young; therefore it was much more common to have an older witness and a younger suspect than vice versa. 
Video lineups in England

Table 1. Distributions of crime types, witness ethnicity, and suspect ethnicity across the five sampled police forces, along with suspect, filler, and nonidentification rates.

\begin{tabular}{|c|c|c|c|c|c|}
\hline Police force & 1 & 2 & 3 & 4 & 5 \\
\hline \multicolumn{6}{|c|}{ Lineup outcomes } \\
\hline Suspect ID & $40.54 \%$ & $48.74 \%$ & $33.73 \%$ & $38.83 \%$ & $30.12 \%$ \\
\hline Filler ID & $22.52 \%$ & $23.11 \%$ & $27.71 \%$ & $23.46 \%$ & $37.95 \%$ \\
\hline No ID & $36.94 \%$ & $28.15 \%$ & $38.55 \%$ & $37.71 \%$ & $31.93 \%$ \\
\hline \multicolumn{6}{|c|}{ Crime type } \\
\hline Violence & $40.54 \%$ & $36.13 \%$ & $32.53 \%$ & $39.11 \%$ & $45.78 \%$ \\
\hline Robbery & $17.12 \%$ & $2.52 \%$ & $44.58 \%$ & $32.40 \%$ & $23.49 \%$ \\
\hline Burglary & $10.81 \%$ & $13.03 \%$ & $8.43 \%$ & $12.57 \%$ & $10.24 \%$ \\
\hline Sexual Offences & $0.90 \%$ & $6.30 \%$ & $4.82 \%$ & $4.19 \%$ & $4.82 \%$ \\
\hline Other & $30.63 \%$ & $42.02 \%$ & $9.64 \%$ & $11.73 \%$ & $15.66 \%$ \\
\hline \multicolumn{6}{|c|}{ Witness ethnicity } \\
\hline White & $83.79 \%$ & $96.22 \%$ & $56.02 \%$ & $45.81 \%$ & $87.95 \%$ \\
\hline Black & $7.21 \%$ & $0.42 \%$ & $17.47 \%$ & $14.25 \%$ & $0.60 \%$ \\
\hline South Asian & $7.21 \%$ & $0.42 \%$ & $15.66 \%$ & $33.24 \%$ & $7.22 \%$ \\
\hline Other & $1.80 \%$ & $2.94 \%$ & $10.54 \%$ & $6.70 \%$ & $4.21 \%$ \\
\hline \multicolumn{6}{|c|}{ Suspect ethnicity } \\
\hline White & $90.99 \%$ & $92.86 \%$ & $27.11 \%$ & $41.34 \%$ & $60.84 \%$ \\
\hline Black & $7.21 \%$ & $1.68 \%$ & $60.24 \%$ & $32.40 \%$ & $18.07 \%$ \\
\hline South Asian & $0.00 \%$ & $0.84 \%$ & $3.61 \%$ & $18.99 \%$ & $10.84 \%$ \\
\hline Other & $1.80 \%$ & $4.62 \%$ & $9.04 \%$ & $7.26 \%$ & $10.24 \%$ \\
\hline
\end{tabular}


Video lineups in England

Table 2. Percentage of suspect identifications and 95\% confidence intervals, broken down by Suspect Sex, Suspect Ethnicity, and Crime Type.

\begin{tabular}{|c|c|c|c|c|}
\hline & \multirow[t]{2}{*}{ N cases } & \multirow{2}{*}{$\begin{array}{l}\text { Percentage } \\
\text { suspect ID }\end{array}$} & \multicolumn{2}{|c|}{ 95\% Confidence intervals } \\
\hline & & & Lower bound & Upper bound \\
\hline \multicolumn{5}{|c|}{ Suspect Sex } \\
\hline Male & 969 & $37.87 \%$ & $34.51 \%$ & $40.93 \%$ \\
\hline Female & 70 & $55.71 \%$ & $43.78 \%$ & $67.64 \%$ \\
\hline \multicolumn{5}{|c|}{ Suspect Ethnicity } \\
\hline White & 616 & $44.16 \%$ & $40.22 \%$ & $48.09 \%$ \\
\hline Black & 258 & $29.46 \%$ & $23.86 \%$ & $35.06 \%$ \\
\hline South Asian & 94 & $36.17 \%$ & $26.28 \%$ & $46.06 \%$ \\
\hline Other & 71 & $33.80 \%$ & $22.53 \%$ & $45.08 \%$ \\
\hline \multicolumn{5}{|c|}{ Crime type } \\
\hline Violence & 401 & $41.90 \%$ & $37.05 \%$ & $46.75 \%$ \\
\hline Robbery & 254 & $28.74 \%$ & $23.14 \%$ & $34.34 \%$ \\
\hline Burglary & 119 & $38.66 \%$ & $29.78 \%$ & $47.53 \%$ \\
\hline Sexual Offences & 47 & $42.55 \%$ & $27.88 \%$ & $57.23 \%$ \\
\hline Other & 218 & $45.41 \%$ & $38.75 \%$ & $52.07 \%$ \\
\hline
\end{tabular}


Video lineups in England

Table 3. Percentage of filler identifications and 95\% confidence intervals, broken down by Repeated Viewing, Witness Ethnicity, and Crime Type.

\begin{tabular}{|c|c|c|c|c|}
\hline & \multirow[t]{2}{*}{$\mathrm{N}$ cases } & \multirow{2}{*}{$\begin{array}{c}\text { Percentage filler } \\
\text { ID }\end{array}$} & \multicolumn{2}{|c|}{$95 \%$ Confidence Intervals } \\
\hline & & & Lower bound & Upper bound \\
\hline \multicolumn{5}{|c|}{ Repeated Viewing } \\
\hline Additional view(s) & 489 & $38.04 \%$ & $33.72 \%$ & $42.35 \%$ \\
\hline No additional view & 550 & $15.82 \%$ & $12.76 \%$ & $18.88 \%$ \\
\hline \multicolumn{5}{|c|}{ Witness Ethnicity } \\
\hline White & 725 & $28.69 \%$ & $25.39 \%$ & $31.99 \%$ \\
\hline Black & 90 & $23.33 \%$ & $14.43 \%$ & $32.24 \%$ \\
\hline South Asian & 166 & $17.47 \%$ & $11.63 \%$ & $23.31 \%$ \\
\hline Other & 58 & $25.86 \%$ & $14.25 \%$ & $37.48 \%$ \\
\hline \multicolumn{5}{|c|}{ Crime type } \\
\hline Violence & 401 & $30.07 \%$ & $25.66 \%$ & $34.69 \%$ \\
\hline Robbery & 254 & $23.23 \%$ & $18.00 \%$ & $28.46 \%$ \\
\hline Burglary & 119 & $25.52 \%$ & $17.29 \%$ & $33.13 \%$ \\
\hline Sexual Offences & 47 & $31.91 \%$ & $18.08 \%$ & $45.75 \%$ \\
\hline Other & 218 & $22.02 \%$ & $16.47 \%$ & $27.56 \%$ \\
\hline
\end{tabular}


Video lineups in England

Table 4. Associations between categorical predictor variables (Cramér's V).

\begin{tabular}{|c|c|c|c|c|c|c|c|c|c|c|}
\hline & $\begin{array}{c}\text { Witness } \\
\text { Sex }\end{array}$ & $\begin{array}{l}\text { Witness } \\
\text { Ethnicity }\end{array}$ & $\begin{array}{c}\text { Witness- } \\
\text { Victim }\end{array}$ & $\begin{array}{c}\text { Suspect } \\
\text { Sex }\end{array}$ & $\begin{array}{l}\text { Suspect } \\
\text { Ethnicity }\end{array}$ & $\begin{array}{c}\text { Own- } \\
\text { Ethnicity }\end{array}$ & Own-Sex & $\begin{array}{c}\text { Crime } \\
\text { Type }\end{array}$ & $\begin{array}{c}\text { Lineup } \\
\text { Position }\end{array}$ & $\begin{array}{l}\text { Repeat } \\
\text { Viewing }\end{array}$ \\
\hline Witness Sex & 1.00 & .198 & .120 & .126 & .083 & .062 & .843 & .292 & .077 & .073 \\
\hline Witness Ethnicity & & 1.00 & .196 & .084 & .246 & .402 & .138 & .158 & .122 & .049 \\
\hline Witness-Victim & & & 1.00 & .053 & .157 & .103 & .119 & .286 & .043 & .012 \\
\hline Suspect Sex & & & & 1.00 & .067 & .015 & .095 & .098 & .073 & .016 \\
\hline Suspect Ethnicity & & & & & 1.00 & .628 & .062 & .217 & .120 & .063 \\
\hline Own-Ethnicity & & & & & & 1.00 & .043 & .251 & .157 & .004 \\
\hline Lineup position & & & & & & & & & 1.00 & .067 \\
\hline Repeat Viewing & & & & & & & & & & 1.00 \\
\hline
\end{tabular}


Video lineups in England

\section{Figure captions.}

Figure 1. Suspect identification rates plotted against delay.

Note: Data were grouped so that bins contained a similar number of cases (varying between 71 and 87). Note that the bins span increasingly larger periods of time as delay increases, as there were fewer cases for any given delay.

Figure 2. Suspect identification rates as a function of the difference in age between the witness and the suspect.

Note: Data were grouped so that bins contained a similar number of cases (varying between 74 and 111). Note that the bins span increasingly larger age ranges as age difference increases, as there were fewer cases for any given age difference.

Figure 3. Filler identification rates as a function of the difference in age between the witness and the suspect.

Note: Data were grouped so that bins contained a similar number of cases (varying between 74 and 111). Note that the bins span increasingly larger age ranges as age difference increases, as there were fewer cases for any given age difference. 
Video lineups in England

Figure 1. Suspect identification rates plotted against delay.

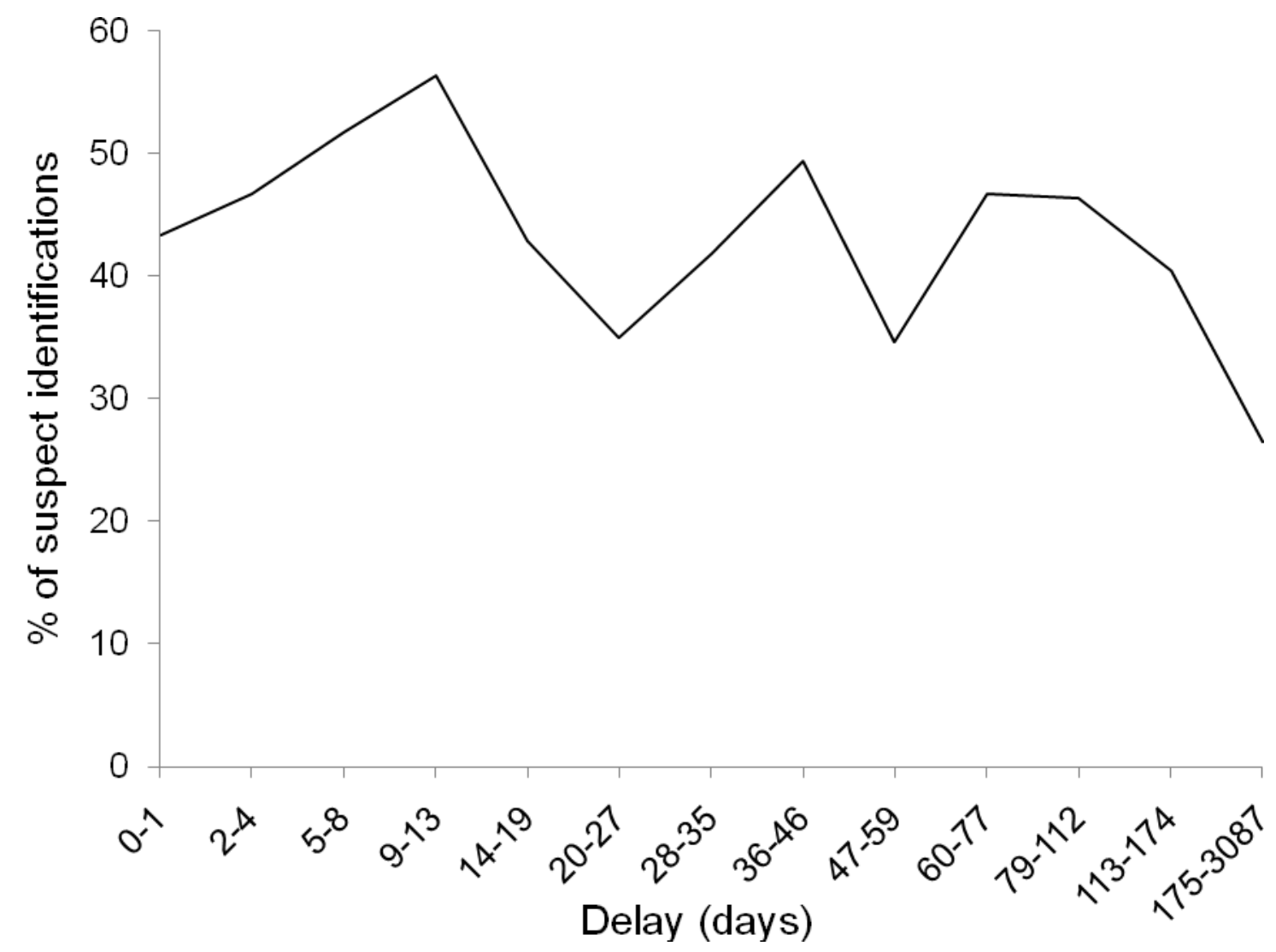

Note: Data were grouped so that bins contained a similar number of cases (varying between 71 and 87 ). Note that the bins span increasingly larger periods of time as delay increases, as there were fewer cases for any given delay. 
Video lineups in England

Figure 2. Suspect identification rates as a function of the difference in age between the witness and the suspect.

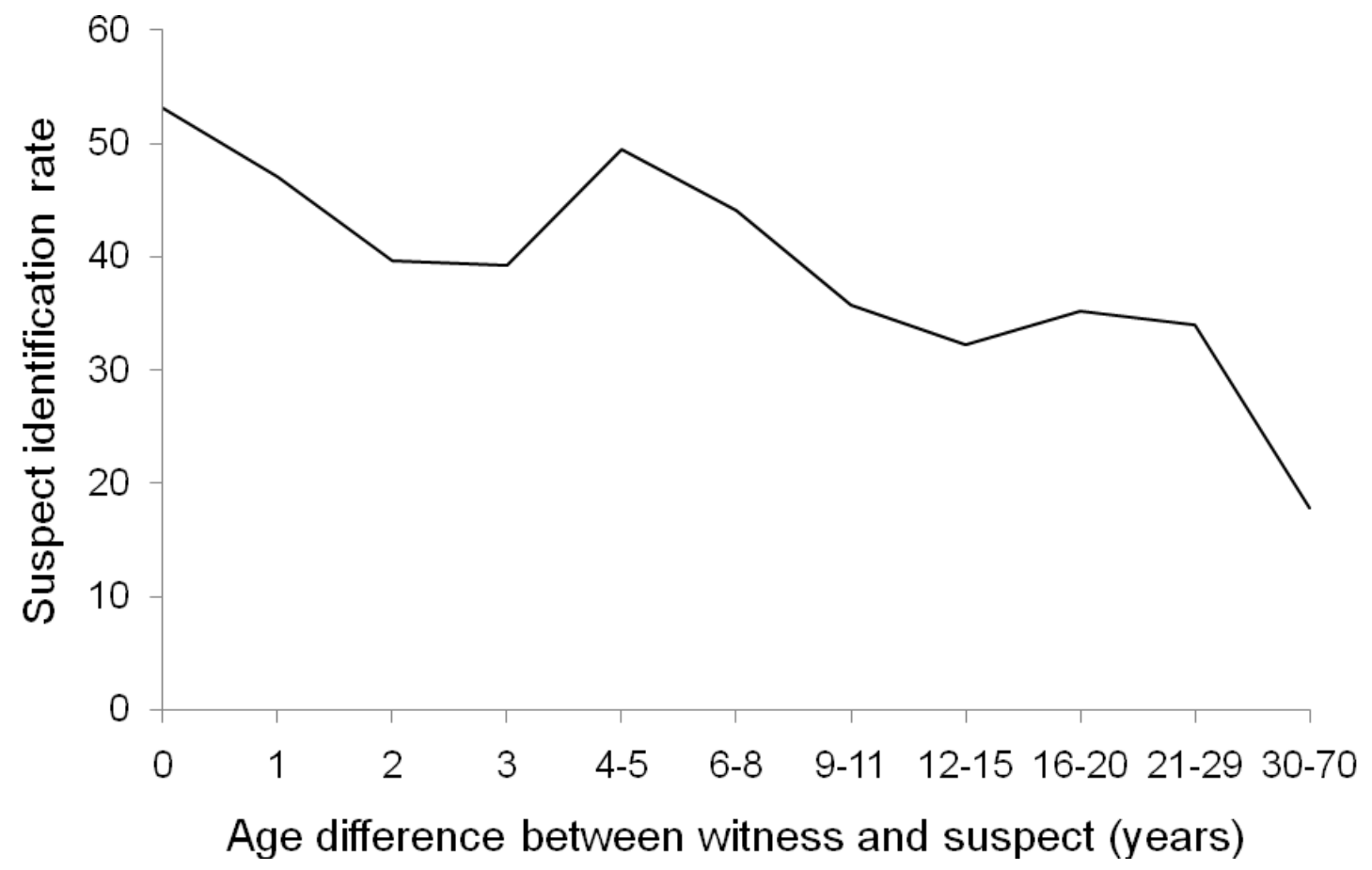

Note: Data were grouped so that bins contained a similar number of cases (varying between 74 and 111). Note that the bins span increasingly larger age ranges as age difference increases, as there were fewer cases for any given age difference. 
Video lineups in England

Figure 3. Filler identification rates as a function of the difference in age between the witness and the suspect.

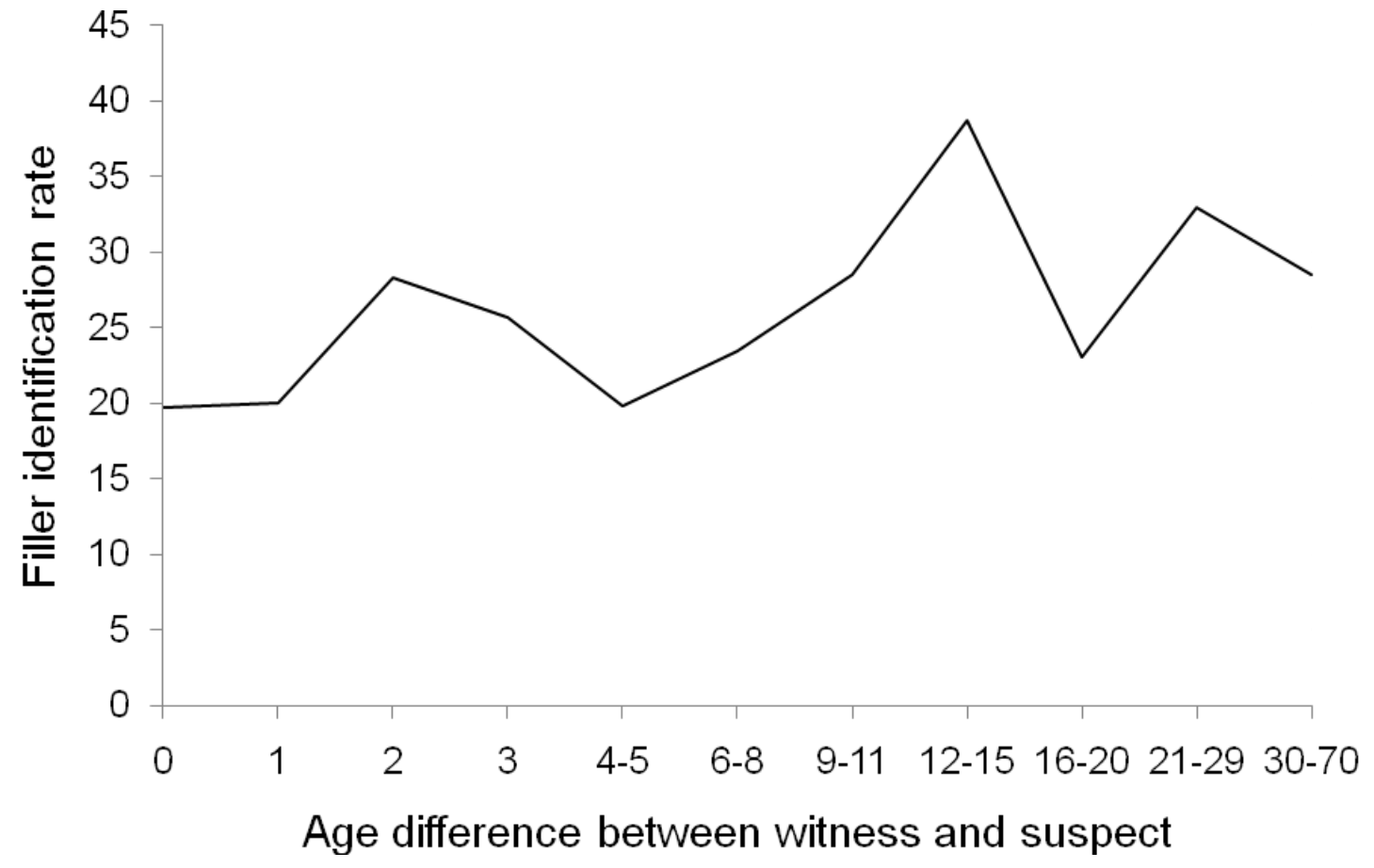

Note: Data were grouped so that bins contained a similar number of cases (varying between 74 and 111). Note that the bins span increasingly larger age ranges as age difference increases, as there were fewer cases for any given age difference. 